\title{
EFEITO DO TIPO DE DESCASQUE E DA TEMPERATURA DE ARMAZENAMENTO NA QUALIDADE DE LARANJAS 'PERA' MINIMAMENTE PROCESSADAS ${ }^{1}$
}

\author{
JULIANA RODRIGUES DONADON², JOSÉ FERNANDO DURIGAN³, BIANCA SARZI DE SOUZA ${ }^{4}$, \\ GUSTAVO HENRIQUE DE ALMEIDA TEIXEIRA ${ }^{5}$, JULIANA SANCHES ${ }^{6}$
}

\begin{abstract}
RESUMO - O objetivo deste trabalho foi avaliar a influência do tipo de descasque, manual, mecânico e enzimático, e do armazenamento, a $5^{\circ} \mathrm{C}$ e $10^{\circ} \mathrm{C}$ e ambiente $\left(21-23^{\circ} \mathrm{C}\right)$, na vida útil de laranjas 'Pêra' do tipo Rio, minimamente processadas. As laranjas foram colhidas maduras, e imediatamente lavadas, higienizadas e descascadas. Após a eliminação da casca, as frutas foram desinfetadas e embaladas em bandejas de isopor revestidas com filme PVC esticável. Durante o armazenamento sob as diferentes temperaturas, avaliaram-se a aparência, a quantidade de suco drenado, o aparecimento de podridões, a perda de massa fresca, a intensidade respiratória, os conteúdos de $\mathrm{O}_{2}$ e $\mathrm{CO}_{2}$ no interior das embalagens, a coloração, os teores de ácido ascórbico (AA) e de sólidos solúveis totais (SST), e acidez titulável (AT), assim como a relação SST/AT. Foram realizadas avaliações microbiológicas, bem como testes de aceitabilidade e de preferência de compra pelo consumidor. Somente os produtos descascados enzimaticamente (DE) apresentaram perda de suco, que aumentou com o tempo e a temperatura de armazenamento. A perda de massa fresca ocorreu em todos os produtos, mas os $\mathrm{DE}$ e os armazenados a $21-23^{\circ} \mathrm{C}$ apresentaram os maiores valores. Todas as laranjas processadas apresentaram pico respiratório na primeira hora após o descascamento, seguido de redução e estabilização. O descascamento enzimático e as menores temperaturas de armazenamento levaram aos teores mais elevados de $\mathrm{O}_{2}$ e aos mais baixos de $\mathrm{CO}_{2}$, nas embalagens. As frutas processadas apresentarem baixa contagem de microrganismos mesófilos, psicrófilos e coliformes totais, e ausência de coliformes fecais. Podridões apareceram nas descascadas manual (DM) e mecanicamente (DME) após 13 dias, 8 dias e 4 dias a $5^{\circ} \mathrm{C} \mathrm{e} 10^{\circ} \mathrm{C}$ e ambiente $\left(21-23^{\circ} \mathrm{C}\right)$, respectivamente. Os produtos obtidos com descascamento manual (DM) não diferiram dos DME ou DE, quanto aos teores de AT, SST e AA e relação SST/AT. Os produtos DM e DME, armazenados a $5^{\circ} \mathrm{C}$, foram os preferidos pelos provadores e apresentaram boa aparência por 19 dias e bom sabor por 23 dias. Os DE e armazenados a $5^{\circ} \mathrm{C}$ apresentaram boa aparência por 4 dias e sabor desagradável no $1^{\circ}$ dia.
\end{abstract}

Termos para indexação: cítrus, processamento mínimo, vida útil

\section{EFFECT OF TYPE OF PEELING AND STORAGE TEMPERATURE ON QUALITY OF MINIMALLY PROCESSED "PERA-RIO" ORANGES}

\begin{abstract}
The aim of this work was to evaluate the influence of type of peeling, manual, mechanic and enzymatic, and temperature of storage, $5^{\circ} \mathrm{C}$, $10^{\circ} \mathrm{C}$ and ambient $\left(21-23^{\circ} \mathrm{C}\right)$ on the shelf-life of minimally processed 'Pera' type Rio oranges. Ripe oranges were picked and immediately washed and peeled. After peeled, fruits were disinfected and packed on polystyrene trays recovered with stretchable PVC film. During storage, was evaluated the appearance, amount of juice loss, rotting, loss of fresh mass, respiratory intensity, level of $\mathrm{O}_{2}$ and $\mathrm{CO}_{2}$ inside the packages, color, contents of total soluble solids (TSS), titratable acidity (TA) and ascorbic acid (AA) and the ratio TSS/TA. Microbiological evaluations were made as well as testing acceptance and preference by the consumer. Only enzymatically peeled products presented juice loss that increased with storage time. There was continuous loss of fresh mass in every product, but peeled products stored at $21-23^{\circ} \mathrm{C}$ presented the greatest losses. Processed oranges presented a respiratory peak at the first hour after peeling followed by reduction and stabilization at $11^{\text {th }}-13^{\text {th }}$ hour. The enzymatic peeling and the lowest storage temperatures produces the highest contents of $\mathrm{O}_{2}$ and the lowest of $\mathrm{CO}_{2}$ in packages. Processed fruits presented low counting of microorganisms, mesophilic, psychrotrophs and coliforms. Fecal coliforms were not detected. Rotting appeared on manually and mechanically peeled after 13 days at $5^{\circ} \mathrm{C}, 8$ days at $10^{\circ} \mathrm{C}$ or 4 days at $21-23^{\circ} \mathrm{C}$. Products obtained from manual peeling did not differ from mechanically or enzymatically peeled related to contents of TA, TSS and AA and the ratio (TSS/TA). Products manually or mechanically peeled, and stored at $5^{\circ} \mathrm{C}$, were considered the best by the tasters and presented good appearance during 19 days and good taste for 23 days. Products enzymatically peeled and stored at $5^{\circ} \mathrm{C}$ presented good appearance for four days and unpleasant taste in the first day.
\end{abstract}

Index terms: citrus, minimally processed, shelf-life, fresh-cut

\section{INTRODUÇÃO}

As espécies mais comercializadas dentre as frutas cítricas são as laranjas, as mandarinas e as tangerinas, os limões, as limas e os pomelos (Murata, 2001). Estas frutas possuem forma normalmente arredondada, casca dividida em flavedo e albedo, e a polpa segmentada. São ricas em vitamina $\mathrm{A}$ e $\mathrm{C}$.

O Brasil é um grande produtor de laranjas, com a maior parte de sua produção sendo destinada à industrialização de suco concentrado congelado, apesar de o consumo in natura ser bastante representativo. Em 2003, o volume de laranjas comercializadas na CEAGESP-SP, foi de 127.982 toneladas, das quais, 99.808 toneladas foram de laranjas 'Pêra' (Agrianual, 2004).

$\mathrm{Na}$ utilização das frutas cítricas como produtos frescos, o descascamento é o fator limitante, dada a inconveniência da operação, o cheiro dos óleos essenciais e a perda de suco, daí o interesse de que se ofereça estas frutas sem casca, prontas para o consumo. Isto pode ser conseguido manual e mecanicamente ou utilizando-se de enzimas pectinolíticas, que atuam na estrutura do albedo, facilitando a retirada da casca (Pretel et al., 1997).

Estas frutas têm ainda características fisiológicas e morfológicas adequadas para o preparo de produtos minimamente processados (PMP), pois não são climatéricas e resistem ao armazenamento refrigerado, sem mudanças bioquímicas aparentes (Cantwell, 2000).

Segundo Alves et al. (2000), a cultivar, as condições do desenvolvimento, o ponto de colheita, os cuidados na colheita e manuseio, os padrões de inspeção, assim como a duração e as condições

\footnotetext{
${ }^{1}$ (Trabalho, 119/2004). Recebido: 07/10/2004. Aceito para publicação: 21/12/2004. Parte da dissertação de Mestrado da primeira autora. Financiado pela CAPES.

2 Eng. Agrônoma, mestranda em Produção Vegetal da FCAV/Unesp. Depto. de Tecnologia. Via de Acesso Prof. Paulo Donato Castellane, s/n, 14884-900, JaboticabalSP. Tel (16) 3209-2675, jdonadon@fcav.unesp.br.

${ }^{3}$ Prof. Titular da FCAV/Unesp, jfduri@fcav.unesp.br.

${ }^{4}$ Eng. Agrônoma, M.Sc, doutoranda em Produção Vegetal da FCAV/Unesp, biasarzi@fcav.unesp.br.

${ }^{5}$ Eng. Agrônomo, M.Sc, doutorando em Produção Vegetal da FCAV/Unesp, bacupari@fcav.unesp.br.

${ }^{6}$ Eng. Agrônoma, M.Sc, doutoranda em Produção Vegetal da FCAV/Unesp, jsanches@fcav.unesp.br.
} 
do armazenamento influenciam na qualidade das frutas minimamente processadas.

Dada a exposição dos tecidos internos ao ambiente, os produtos minimamente processados de frutas são altamente perecíveis, exigindo que a temperatura, a atmosfera ambiente e as condições sanitárias sejam controladas para a conservação da qualidade (Durigan, 2000a), o que ainda é bastante difícil de ser conseguido, principalmente devido à falta de conhecimento a respeito do comportamento fisiológico dos produtos preparados (Durigan, 2000b).

O objetivo deste trabalho foi avaliar o efeito do tipo de descasque (manual, mecânico e enzimático) e da temperatura de armazenamento $\left(5^{\circ} \mathrm{C} \mathrm{e} 10^{\circ} \mathrm{C}\right.$ e ambiente a $\left.21-23^{\circ} \mathrm{C}\right)$ na qualidade de laranjas 'Pêra' do tipo Rio, minimamente processadas.

\section{MATERIAL E MÉTODOS}

Laranjas 'Pêra' do tipo Rio, produzidas na região de JaboticabalSP, foram cuidadosamente colhidas no ponto de maturação comercial, ou seja, quando amostras ao acaso apresentavam 9,61 ${ }^{\circ}$ Brix, 0,523 g. 100 $\mathrm{g}^{-1}$ de acidez titulável e ratio de 17,73, e transportadas ao Laboratório de Tecnologia dos Produtos Agrícolas da FCAV/UNESP/Jaboticabal, onde foram imediatamente lavadas com detergente neutro $(20 \mathrm{~mL}$ de detergente. $\left.\mathrm{L}^{-1}\right)$, desinfetadas por imersão em água clorada (200 mg de cloro. $\left.\mathrm{L}^{-1}\right)$. As laranjas destinadas ao descasque enzimático foram mantidas em ambiente higienizado, a $21-23^{\circ} \mathrm{C}$, por 2 dias. As frutas destinadas aos descasques manual e mecânico foram refrigeradas por uma noite, em câmara fria a 10$12^{\circ} \mathrm{C}$, antes de serem descascadas, o que foi feito com facas afiadas ou com descascador da marca LUCRE ${ }^{\circledR}$, respectivamente. O descascamento enzimático foi feito imergindo as frutas em solução, a $10 \mathrm{~mL} \cdot \mathrm{L}^{-1}$, do produto Peelzym $^{\circledR}$ (Novozymes Latin América Ltda) a $31^{\circ} \mathrm{C}$, com a utilização de vácuo a 665 mbar, por 5 minutos (Frenkel et al., 1969). Antes da imersão, as frutas foram submetidas a 5 cortes equatoriais e 4 longitudinais, com profundidade de $4,5 \mathrm{~mm}$, de modo que a polpa não fosse atingida, para absorção da solução enzimática (Donadon, et. al, 2003). As frutas tratadas eram incubadas por 40 minutos, a $21-23^{\circ} \mathrm{C}$, antes de serem descascadas.

Os descascamentos manual e mecânico eliminaram o flavedo e parte do albedo, enquanto o enzimático retirou o flavedo e o albedo. Os três tipos foram executados a $10-12^{\circ} \mathrm{C}$ e em condições higiênicas. $\mathrm{O}$ ambiente de preparo, assim como todos os utensílios e embalagens foram previamente higienizados com água clorada $\left(200 \mathrm{mg}\right.$ de cloro. $\left.\mathrm{L}^{-1}\right)$. Os operadores foram protegidos com aventais plásticos e luvas de borracha, utilizando também máscaras e gorros apropriados

Depois de descascadas, as frutas foram enxaguadas com água fria e clorada ( $\left.30 \mathrm{mg} \cdot \mathrm{L}^{-1}\right)$, escorridas por 3 minutos e embaladas inteiras, em grupos com três unidades, em bandejas de isopor $(17 \times 17 \times 1,5 \mathrm{~cm})$, revestidas com filme de cloreto de polivinila (PVC) esticável. As descascadas enzimaticamente, antes de serem desinfetadas, foram imersas em solução de dodecil sulfato de sódio a $1 \%$ por 30 segundos, para inativação da atividade residual da solução enzimática (Helenius \& Simons, 1975)

Os produtos foram armazenados a $5^{\circ} \mathrm{Ce} 10^{\circ} \mathrm{C}$ e ao ambiente $(21-$ $23^{\circ} \mathrm{C}$ ). Durante o armazenamento, estes foram avaliados, em dias alternados e em 5 repetições, quanto à aparência, podridões e perda de massa fresca. Os frutos, depois de pesados, tinham a aparência avaliada segundo uma escala de pontos, onde: $1=$ ótimo; $2=$ bom; $3=$ regular; $4=$ ruim, e $5=$ péssimo, com nota de descarte igual a 3 , e o aparecimento de podridões através de observação visual e identificação dos patógenos pelo Laboratório de Fitopatologia do Departamento de Defesa Fitossanitária da FCAV/UNESP.

A intensidade respiratória foi avaliada, antes e após o processamento mínimo, colocando-se massa conhecida dos frutos ou seus produtos em jarros $(2,5 \mathrm{~L})$ hermeticamente fechados por uma hora, dos quais se tomavam alíquotas de $0,3 \mathrm{~mL}$ do ar interno, antes e depois deste tempo, nas quais se determinava o teor de $\mathrm{CO}_{2}$ em Cromatógrafo CG Finnigan 9001. A quantidade de $\mathrm{CO}_{2}$ produzida no período permitia quantificar a intensidade respiratória dos materiais avaliados.
Os teores de $\mathrm{O}_{2}$ e $\mathrm{CO}_{2}$ nas embalagens foram determinados, em dias alternados, tomando-se amostras $(0,3 \mathrm{~mL})$ dos gases do interior das embalagens e analisando-as no cromatógrafo CG Finnigan 9001.

As laranjas também foram avaliadas, a cada 3 dias, e em duplicata, quanto à porcentagem de suco perdido, através da relação percentual entre o peso do produto e o peso do líquido drenado; coloração, usandose reflectômetro MINOLTA CR 200b; teores de sólidos solúveis totais (SST) e de acidez titulável (AT), segundo metodologia da AOAC (1997) e de ácido ascórbico (Rangana, 1977) e relação SST/AT.

Avaliações microbiológicas quanto à contagem de mesófilos, psicrófilos e presença de coliformes foram realizadas semanalmente (APHA, 1992; ICMSF, 1978), assim como os testes de aceitabilidade em comparação ao produto fresco, em que se avaliou a textura $(0=$ muito duro; $5=$ adequada, e $10=$ muito mole); o sabor $(0=$ muito ruim; $5=$ adequado, e $10=$ muito bom), e a preferência ( $0=$ gostei muito; e $10=$ desgostei muito), utilizando-se de testes pareados e escala não-estruturada.

A evolução da massa fresca foi analisada estatisticamente, através de regressão polinomial (Gomes, 1977) e as equações do $1^{\circ}$ grau comparadas quanto ao paralelismo, através do teste $\mathrm{t}$, conforme o proposto por Neter et al. (1978)

As análises físico-químicas e a coloração foram conduzidas segundo um delineamento inteiramente casualizado, em esquema fatorial $3 \times 3$ ( 3 tipos de descasque e 3 temperaturas de armazenamento), com 2 repetições. Os resultados da análise sensorial foram analisados usandose de delineamento em blocos casualizados. As comparações entre médias foram feitas pelo teste de Tukey, a $5 \%$ de probabilidade.

\section{RESULTADOS E DISCUSSÃO}

Os produtos descascados manual e mecanicamente apresentaram boa aparência $($ nota $=2)$ por 19 dias, 11 dias e por 2 dias quando armazenados a $5^{\circ} \mathrm{Ce} 10^{\circ} \mathrm{C}$ e ambiente $\left(21-23^{\circ} \mathrm{C}\right)$, respectivamente. Os provenientes do descasque enzimático apresentaram boa aparência por 4 dias, quando armazenados a $5^{\circ} \mathrm{Ce} 10^{\circ} \mathrm{C}$ e por 1 dia a $21-23^{\circ} \mathrm{C}$.

Os descascamentos, manual e mecânico, não levaram as frutas a perder suco durante o armazenamento, enquanto o enzimático implicou perda crescente com o tempo de armazenamento e tanto mais elevada quanto maior a temperatura deste armazenamento $\left(5^{\circ} \mathrm{C}=6,95 \% \mathrm{em} 15\right.$ dias, $10^{\circ} \mathrm{C}=6,45 \%$ em 6 dias e $21-23^{\circ} \mathrm{C}=9,75 \%$ em 3 dias). PAO et al. (1996) também relataram a ocorrência de suco drenado em embalagens contendo laranjas descascadas enzimaticamente e armazenadas a $5^{\circ} \mathrm{C}, 10^{\circ} \mathrm{Ce} 15^{\circ} \mathrm{C}$.

Todos os produtos minimamente processados apresentaram ausência de coliformes fecais e contagem muito baixa de coliformes totais. Quando armazenados a $5^{\circ} \mathrm{C}$ e $10^{\circ} \mathrm{C}$, apresentaram baixa contagem de mesófilos e psicrófilos (Tabela 1), atestando a eficiência das práticas sanitizantes adotadas durante a preparação destes produtos e a importância do armazenamento a baixas temperaturas.

Durante o armazenamento, algumas embalagens contendo laranjas descascadas manual ou mecanicamente apresentaram podridões causadas pelo Pennicillim digitatum. Isto ocorreu no $13^{\circ}$ dia a $5^{\circ} \mathrm{C}$, no $8^{\circ}$ dia a $10^{\circ} \mathrm{C}$ e no $4^{\circ}$ dia a $21-23^{\circ} \mathrm{C}$. A porcentagem de ocorrência foi baixa (4$9 \%$ ) nos produtos a $5^{\circ} \mathrm{C}$ e $10^{\circ} \mathrm{C}$ e elevada $(60 \%)$ nos ao ambiente

A massa fresca, das laranjas minimamente processadas, decresceu de maneira constante em todos os tratamentos. As descascadas enzimaticamente apresentaram maior perda de massa em relação às manual e mecanicamente, quando a $5^{\circ} \mathrm{C}$ e $10^{\circ} \mathrm{C}$, as quais não diferiram entre si. A $21-23^{\circ} \mathrm{C}$ (ambiente), as descascadas manualmente apresentaram as maiores perdas (Tabela 2).

Após 3 dias de armazenamento, os frutos descascados manual e mecanicamente apresentavam textura adequada $(4,78)$ e bom sabor $(6,65)$, que se mantiveram ao longo do período de armazenamento. Os descascados enzimaticamente apresentaram, no $1^{\circ}$ dia, textura adequada $(4,77)$, mas sabor desagradável $(1,07)$, que fez com que estes produtos não fossem testados. Os provadores preferiram os produtos obtidos com descasque manual ou mecânico, independentemente da temperatura de armazenamento, que, quando comparados com a fruta fresca durante 
TABELA 1 - Contagem microbiana apresentada pelas laranjas 'Pêra-Rio' minimamente processadas obtidas com descasque manual, mecânico e enzimático, e armazenadas sob diferentes temperaturas $\left(5^{\circ} \mathrm{C}\right.$ e $10^{\circ} \mathrm{C}$ e ambiente a $\left.21-23^{\circ} \mathrm{C}\right)$.

\begin{tabular}{|c|c|c|c|c|}
\hline Tratamento & $\begin{array}{l}\text { Tempo } \\
\text { (dia) }\end{array}$ & $\begin{array}{c}\text { Mesófilos } \\
\text { (UFC/g) }\end{array}$ & $\begin{array}{l}\text { Psicrófilos } \\
\text { (UFC/g) }\end{array}$ & $\begin{array}{c}\text { Coliformes Totais } \\
\left(\mathrm{n}^{\circ} / \mathrm{g}\right)\end{array}$ \\
\hline \multicolumn{5}{|l|}{ Manual } \\
\hline \multirow[t]{3}{*}{$5^{\circ} \mathrm{C}$} & 3 & $<1.10^{1}$ & $<1.10^{1}$ & $<3,0$ \\
\hline & 14 & $<1.10^{1}$ & $3.10^{1}$ & $<3,0$ \\
\hline & 21 & $<1.10^{1}$ & $5.10^{1}$ & $<3,0$ \\
\hline \multirow[t]{2}{*}{$10^{\circ} \mathrm{C}$} & 3 & $<1.10^{1}$ & $<1.10^{1}$ & $<3,0$ \\
\hline & 14 & $<1.10^{1}$ & $7,3.10^{2}$ & $<3,0$ \\
\hline Ambiente & 3 & $2,5.10^{2}$ & $2,5.10^{2}$ & $>1,1.10^{1}$ \\
\hline \multicolumn{5}{|l|}{ Mecânico } \\
\hline \multirow[t]{2}{*}{$5^{\circ} \mathrm{C}$} & 3 & $<1.10^{1}$ & $<1.10^{1}$ & $<3,0$ \\
\hline & 21 & $5.10^{1}$ & $13.10^{3}$ & $<3,0$ \\
\hline \multirow[t]{2}{*}{$10^{\circ} \mathrm{C}$} & 3 & $<10.10^{1}$ & $<1.10^{1}$ & $<3,0$ \\
\hline & 14 & $<10.10^{1}$ & $<1.10^{1}$ & $<3,0$ \\
\hline Ambiente & 3 & $4,0.10^{2}$ & $2,5.10^{2}$ & $>1,1.10^{1}$ \\
\hline \multicolumn{5}{|l|}{ Enzimático } \\
\hline \multirow[t]{2}{*}{$5^{\circ} \mathrm{C}$} & 3 & $3.10^{1}$ & $3.10^{1}$ & $<3,0$ \\
\hline & 12 & $9.10^{1}$ & $7.10^{1}$ & $<3,0$ \\
\hline $10^{\circ} \mathrm{C}$ & 3 & $<1.10^{1}$ & $<1.10^{1}$ & $<3,0$ \\
\hline Ambiente & 3 & $3,2.10^{4}$ & $1,2.10^{4}$ & $1,1.10^{1}$ \\
\hline
\end{tabular}

TABELA 2 - Equações de regressão, representativas da evolução da massa fresca de laranjas 'Pêra-Rio' minimamente processadas obtidas com descasque manual, mecânico e enzimático, e armazenadas sob diferentes temperaturas $\left(5^{\circ} \mathrm{C} \mathrm{e} 10^{\circ} \mathrm{C}\right.$ e ambiente a $\left.21-23^{\circ} \mathrm{C}\right)$.

\begin{tabular}{|c|c|c|c|}
\hline Tratamentos & $\mathrm{Y}=\mathrm{A}-\mathrm{BX}^{\mathrm{a}}$ & $\mathrm{r}$ & Paralelismo \\
\hline Manual & $\mathrm{Y}=99,9891-0,0654 \mathrm{X}$ & $-0,9824 * *$ & $\mathrm{f}$ \\
\hline $10^{\circ} \mathrm{C}$ & $Y=99,8921-0,1193 X$ & $-0,9955 * *$ & d \\
\hline Ambiente & $Y=99,9300-0,6600 X$ & $-0,9990 * *$ & $\mathrm{~b}$ \\
\hline Mecânico $5^{\circ} \mathrm{C}$ & $Y=99,9988-0,0671 X$ & $-0,9775 * *$ & $\mathrm{f}$ \\
\hline $10^{\circ} \mathrm{C}$ & $Y=99,9168-0,1277 X$ & $-0,9977 * *$ & d \\
\hline Ambiente & $Y=99,9700-0,5650 X$ & $-0,9998 * *$ & $\mathrm{a}$ \\
\hline Enzimático $5^{\circ} \mathrm{C}$ & $Y=99,8959-0,0943 X$ & $-0,9858 * *$ & $\mathrm{e}$ \\
\hline $10^{\circ} \mathrm{C}$ & $Y=99,9700-0,3150 X$ & $-0,9992 * *$ & $\mathrm{c}$ \\
\hline Ambiente $^{\mathrm{b}}$ & $Y=100,0020-0,2515 X$ & $-1,0000 * *$ & - \\
\hline
\end{tabular}

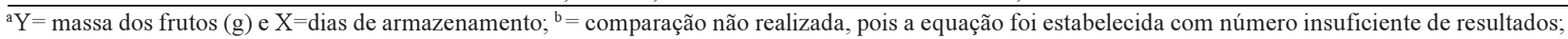

** significativo a $1 \%$ de probabilidade.

a vida útil, não se mostraram diferentes. Os resultados obtidos com o armazenamento a $5^{\circ} \mathrm{C}$ e $10^{\circ} \mathrm{C}$ das frutas descascadas mecânica e manualmente foram melhores que os relatados por Pretel et al. (1998), ou seja, vida útil de uma semana para laranjas descascadas manualmente e armazenadas a $4^{\circ} \mathrm{C}$. No entanto, não se comprovou a durabilidade relatada por Rocha et al. (1995), ou seja, da conservação de laranjas descascadas enzimaticamente e armazenadas a $4^{\circ} \mathrm{C}$, por até 5 dias.

As laranjas minimamente processadas apresentaram aumento na atividade respiratória uma hora após o processamento, seguido de redução e estabilidade (Figura 1). A intensidade respiratória dos produtos foi tanto mais elevada quanto maior a temperatura de armazenamento. As frutas descascadas enzimaticamente e armazenadas ao ambiente apresentaram metabolismo menos intenso quando comparadas ao descasque manual e ao mecânico. Arruda et al. (2004) também observaram aumento na atividade respiratória de laranjas 'Pêra' após o descascamento e que as frutas com albedo respiraram mais intensamente que as sem albedo.

Observaram-se redução nos teores de $\mathrm{O}_{2}$ e aumento nos de $\mathrm{CO}_{2}$ no interior das embalagens, sendo que ambos foram mais acentuados no $1^{\circ}$ dia de armazenamento e nas embalagens a $21-23^{\circ} \mathrm{C}$ (Figura 2). Os teores de $\mathrm{O}_{2} \mathrm{eCO}_{2}$ tenderam à estabilidade, a partir do segundo dia de armazenamento. Nas embalagens ao ambiente, os teores de $\mathrm{CO}_{2}$ reduziram e os de $\mathrm{O}_{2}$ aumentaram a partir do $4 \%$. Os produtos obtidos com descasque enzimático apresentaram os teores mais elevados de $\mathrm{O}_{2}$ e os mais baixos de $\mathrm{CO}_{2}$

Nas três temperaturas testadas, os produtos obtidos com descasque manual não diferiram estatisticamente dos obtidos com descasque mecânico e enzimático quanto ao ângulo de cor $\left(96^{\circ}-117^{\circ}\right)$ e à cromaticidade (20-29). Com o descasque enzimático, os produtos
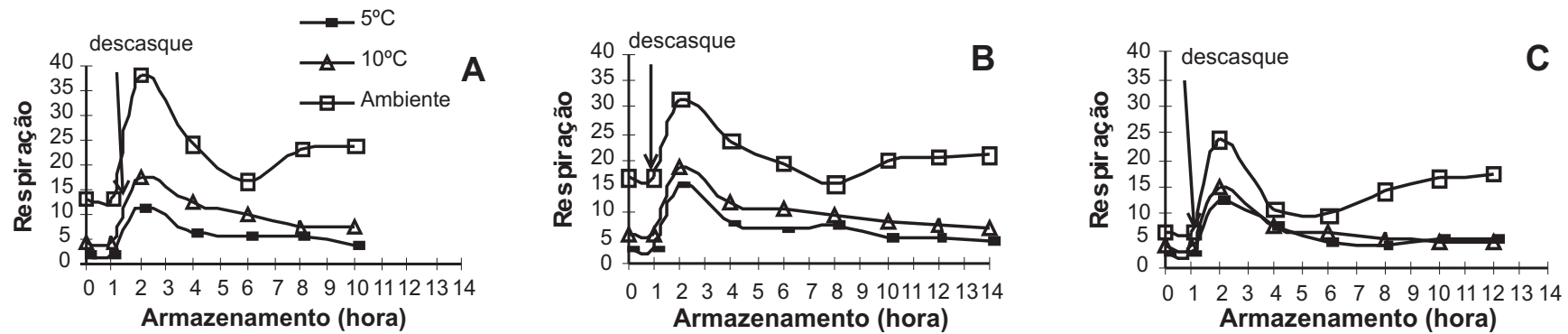

FIGURA 1 - Respiração de laranjas 'Pêra-Rio' $\left(\mathrm{mLCO}_{2} \cdot \mathrm{kg}^{-1} \cdot \mathrm{h}^{-1}\right)$ antes e depois de descascadas manual (A), mecânica (B) e enzimaticamente (C), e armazenadas sob diferentes temperaturas $\left(5^{\circ} \mathrm{C} \mathrm{e} 10^{\circ} \mathrm{C}\right.$ e ambiente a $\left.21-23^{\circ} \mathrm{C}\right)$. 
tornaram-se mais claros ao longo do armazenamento, evidenciado pelo aumento na luminosidade. Já com os descasques manual e mecânico, e à temperatura ambiente, observou-se o efeito contrário, ou seja, uma leve tendência ao escurecimento, de 91,82 para 88,93. Resultados semelhantes também foram obtidos por Rocha et al. (1995), que trabalharam com laranjas descascadas e armazenados a $4^{\circ} \mathrm{C}$.

Não se observaram diferenças significativas nos teores de sólidos solúveis totais (SST), acidez titulável (AT), ácido ascórbico (AA) e relação SST/AT em laranjas 'Pêra-Rio' minimamente processadas com diferentes processos de descascamento e armazenadas nas diferentes temperaturas. Nestes produtos, os teores médios de AT foram de $0,585 \pm$ $0,103 \mathrm{~g} .100 \mathrm{~mL}^{-1}$, os de SST de $9,33 \pm 0,80{ }^{\circ}$ Brix, os de AA de $31,48 \pm 5,44$ mg. $100 \mathrm{~g}^{-1} \mathrm{e}$ a relação SST/AT de $16,35 \pm 2,72$, o que também foi observado por Pretel et al. (1998).



FIGURA 2 - Concentração de $\mathrm{O}_{2}$ e de $\mathrm{CO}_{2}$ no interior das embalagens contendo laranjas 'Pêra-Rio' descascadas manual (M), mecânica (ME) e enzimaticamente $(\mathrm{E})$, e armazenadas sob diferentes temperaturas, $5^{\circ} \mathrm{Ce} 10^{\circ} \mathrm{C}$ e ambiente $\left(21-23^{\circ} \mathrm{C}\right)$.

\section{CONCLUSÕES}

A temperatura de $5^{\circ} \mathrm{C}$ foi a mais eficiente para a conservação dos produtos descascados manual ou mecanicamente, que apresentaram vida útil de 12 dias, limitada pelo aparecimento de podridões. O descasque enzimático proporcionou aos produtos sabor desagradável no $1^{\circ}$ dia de armazenamento.

\section{REFERÊNCIAS}

AGRIANUAL 2004: anuário da agricultura brasileira. São Paulo: FNP -
Consultoria e Comércio, 2004. p.291-292.

ALVES, R. E.; SOUZA FIHO, M. de S. M. de; BASTOS, M. S. R., FILGUEIRAS, H. A. C.; BORGES, M. de F. Pesquisa em processamento mínimo de frutas no Brasil. In: ENCONTRO NACIONAL SOBRE PROCESSAMENTO DE FRUTAS E HORTALIÇAS, 2., 2000, Viçosa-MG Palestras...Viçosa: UFV, 2000. p.75-88

AMERICAN PUBLIC HEALTH ASSOCIATION. Committee on Microbiological Methods for Foods. Compendium of methods for the microbiological examination of foods. 3.ed. Washington: American Public Health Association, 1992. 1.219p. 
Official methods of analysis of de Association of Official Analytical Chemists. 16 ed. Washington: AOAC, 1997. v.2, p.37-45.

ARRUDA, M. C.; JACOMINO, A. P.; CAPISTRANO, R. M.; TREVISAN, M. J. Taxa respiratória de laranja 'Pêra' submetida a diferentes níveis de processamento mínimo. In ENCONTRO NACIONAL SOBRE PROCESSAMENTO MÍNIMO DE FRUTAS E HORTALIÇAS, 3., 2004, Viçosa. Palestras, Resumos e Oficinas... Viçosa: UFV, 2004. p. 143.

CANTWELL, M. Preparation and quality of fresh cut produce. In: ENCONTRO NACIONAL SOBREPROCESSAMENTO DE FRUTAS E HORTALIÇAS, 2., 2000, Viçosa. Palestras...Viçosa: U F V, 2000. p.156-182.

DONADON, J. R.; DURIGAN, J. F.; SOUZA, B. S.; MATTIUZ, B. Otimização do descasque enzimático de laranjas 'Pêra-Rio'. In: SIMPÓSIOLATINOAMERICANODE CIÊNCIADE ALIMENTOS, 5., 2003, Campinas-SP. Anais... Campinas: FEA-UNICAMP, 2003, CDRom.

DURIGAN, J. F. O processamento mínimo de frutas. In: CONGRESSO BRASILEIRODE FRUTICULTURA, 16., 2000, Fortaleza . Palestras... Fortaleza: SBF, 2000a, p. 244-253.

DURIGAN, J. F. Processamento mínimo de frutas. In: ENCONTRO NACIONAL SOBRE PROCESSAMENTO DE FRUTAS E HORTALIÇAS, 2., 2000, Viçosa. Palestras...Viçosa: UFV, 2000b. p.8688.

FRENKEL, C.; KLEIN, I.; DILLEY, D. R. Methods for the study of ripening and protein synthesis in intact pome fruits. Phytochemistry, Oxford, v. 8, p. $945-55,1969$.

GOMES, F. P. Curso de estatística experimental. 7. ed. Piracicaba: Nobel, 1977. 430p.
HELENIUS, A.; SIMONS, K. Solubilization of membranes by detergents. Biochemica et Biophysica Acta, Amsterdam, v. 415, p. 29-79, 1975.

INTERNATIONAL COMMITTEE ON MICROBIOLOGICAL SPECIFICATION FOR FOOD. Microrganisms in foods. I: their significance and methods of enumeration. 2. ed. Toronto: University Press, 1978. 434p

MURATA, T. Citrus. In: MITRA, S. K.(Ed.). Postharvest physiology and storage of tropical and subtropical fruits. CAB International, 2001. p. $21-47$.

NETER, J.; WASSERMAN, W.; WHITMORE, G. A. Applied linear statistical models. Massachussetts: Allyn and Bacon, IAC, 1978. $745 \mathrm{p}$.

PAO, S.; PETRACEK, P.D.; BROWN, G.E. Effect of infusion method on peel removal and storage quality of citrus. HortTechnology, Alexandria, v.6, n.4, p.409-413, 1996.

PRETEL, M.T.; LOZANO, P.; RIQUELME, F.; ROMOJARO, F. Pectic enzymes in fresh fruit processing: optimization of enzyme peeling of oranges. Process Biochemistry, London, v.32, n. 1, p.43-49, 1997.

PRETEL, M.T.; FERNANDEZ, P.S.; ROMOJARO, F.; MARTINEZ, A. The effect of modified atmosphere packaging on 'ready-to-eat' oranges. Lebensmittel-wissenschaft und Technologie, London, v.31, p.322-328, 1998.

RANGANA, S. Manual of analysis of fruit and vegetable products. New Delhi: McGraw-Hill, 1997. 634p.

ROCHA, A.M.C.N.; BROCHADO, C.M.; KIRBY, R., MORAIS, A.M.M.B. Shelf-life of chilled cut orange determined by sensory quality. Food Control, Guildford, v.6, p.317-322, 1995. 